\title{
Tributação sobre Consumo: o esforço em onerar mais quem ganha menos ${ }^{1}$
}

\author{
Taxation over Consumption: over taxing the low-income tax payers
}

\author{
Valcir Gassen \\ Pedro Júlio Sales D’Araújo \\ Sandra Regina da F. Paulino
}

Resumo: Este artigo tem como objetivo examinar a tributação sobre o consumo e o peso que ela representa na renda da população brasileira, demonstrando o quão regressiva é nossa matriz tributária. Após uma análise sucinta das espécies tributárias que incidem sobre o consumo, abordou-se nosso sistema tributário sob a perspectiva da capacidade contributiva, como princípio limitador do poder de tributar e garantidor do chamado mínimo existencial. Logo em seguida, discutiu-se a relação desses tributos com a renda de nossa população. Por fim, formulou-se propostas alternativas para o atual modelo, com o intuito de instigar o debate acerca da necessidade de se pensar em uma reforma tributária que permita alcançar uma maior justiça social.

Palavras-chave: Tributação sobre o Consumo. Capacidade Contributiva. Justiça Tributária.

\begin{abstract}
This article aims to analyze the taxation over consumption and the influence that it represents in the income of the Brazilian population, demonstrating how our tributary system is regressive. After a brief analysis of tax species that rest upon over the consumption, we will be addressing our taxation system from the viewpoint of ability to pay, as a limiter principle of the power to tax and guarantor of so-called existential minimum. Shortly thereafter, we will work with the relationship of these taxes with the income of our population. Finally, it will be proposed alternatives to the current model, with the intention to stimulate the discussion about the need to consider a tax reform that enable us to achieve a bigger social justice.
\end{abstract}

Keywords: Taxation over Consumption. Ability to Pay. Tax Justice.

1 Os autores deste artigo são membros do Grupo de Pesquisa Estado, Constituição e Direito Tributário da Faculdade de Direito da Universidade de Brasília (UnB).

Recebido em: 19/09/2012.

Revisado em: 05/02/2013.

Aprovado em: 03/04/2013. 


\section{Introdução}

O presente artigo tem como objeto fazer um exame da principal fonte de arrecadação de receitas de nosso Estado, a tributação sobre o consumo, e mostrar como essa escolha de política fiscal representa uma violação ao princípio da capacidade contributiva, culminando na transformação de nossa matriz tributária em uma das mais regressivas do mundo.

O trabalho será desenvolvido em quatro tópicos, nos quais se buscará demonstrar como o atual sistema tributário brasileiro, ao onerar aqueles que menos deveriam contribuir, colabora para a formação de uma sociedade menos justa, aprofundando, assim, o abismo social existente em nosso país.

No primeiro tópico, abordaremos os tributos que incidem sobre o consumo, descrevendo de maneira sucinta suas principais características, como fato gerador, base de cálculo, cumulatividade, seletividade e seus contribuintes, tanto de direito, quanto de fato. Em seguida, trataremos do princípio da capacidade contributiva, como limitação ao poder de tributar e forma de garantir o chamado mínimo existencial, que é considerado a condição material necessária para a existência digna dos cidadãos. No terceiro tópico, analisaremos o peso que esses tributos sobre o consumo representam na renda da população brasileira e como eles contribuem para promover a desigualdade social brasileira.

Por fim, serão discutidas alternativas viáveis para alterar a atual matriz tributária. Nessa parte, apresentaremos sugestões que poderiam possibilitar uma atenuação do atual problema da regressividade da tributação e que vêm sendo discutidas durante as últimas décadas nas seguidas propostas de reformas tributárias, mas que ainda aguardam um acordo necessário para sua implementação.

Dessa forma, pretendemos apresentar, de maneira direta, o problema social causado, em considerável medida, pela regressividade da atual matriz tributária e como a sua alteração significa uma melhor redistribuição do encargo fiscal, objetivando a criação de uma sociedade mais justa. 


\section{A Tributação sobre o Consumo: contextualização inicial e aná- lise expositiva dos principais produtos desta natureza no Brasil}

Responsável por incidir nas diversas fases do processo produtivo de bens e serviços, a tributação sobre o consumo é a principal marca da matriz tributária brasileira. Das bases de incidência dos tributos, patrimônio, renda e consumo, esta última responde no Brasil pela maior parte do produto da arrecadação tributária.

Do total da carga tributária brasileira, os tributos incidentes sobre o patrimônio representam $3,52 \%$, sobre a renda $24,14 \%$, e sobre o consumo $68,20 \%^{2}$. Nos países da Organização para a Cooperação e Desenvolvimento Econômico (OCDE), esses indicadores representam respectivamente $5,4 \%, 36,9 \%$ e $30,4 \%{ }^{3}$. Observe-se que, com a soma dos indicadores, não se chega à totalidade. $\mathrm{O}$ restante do percentual é atribuído, em regra, à seguridade social, que não pode ser vista como base de incidência.

Também conhecida por tributação indireta, essa espécie de encargo fiscal tem como uma de suas principais características a sua repercussão econômica na cadeia de consumo, de modo que se opera a transferência do ônus tributário ao consumidor final por intermédio da incorporação do tributo no preço do bem ou serviço, como um custo adicional. Assim, ocorre uma cisão entre o chamado contribuinte de direito, previsto no ordenamento como o responsável pelo fato imponível e que ocupa, consequentemente, o polo passivo da obrigação tributária, e aquele que arca economicamente com o encargo em si, conhecido pela doutrina e jurisprudência por contribuinte de fato.

No Brasil, a tributação sobre o consumo é composta principalmente por três impostos: o Imposto sobre Produtos Industrializados (IPI), o Imposto sobre a Circulação de Mercadorias e Serviços de Transporte In-

\footnotetext{
${ }^{2}$ Cálculo realizado tendo por base Brasil (2011b, p. 16). Tais dados consideram a receita tributária brasileira por base de incidência em 2010 e apontam de forma refletida, com a devida alocação dos percentuais atribuídos à seguridade social, a qual também repercute no consumo de bens e serviços.

${ }^{3}$ Dados relativos ao exercício fiscal de 2008. Para maiores informações, ver OCDE Revenue Statistics (1965-2008).
} 
terestadual e Intermunicipal e de Comunicação (ICMS) e o Imposto Sobre Serviços de Qualquer Natureza (ISS). Cada um desses impostos é de competência de uma entidade política distinta e incide, de alguma forma, sobre o consumo de bens e serviços em nosso país. Neste tópico, tentaremos descrever de maneira sucinta as principais características de cada um desses impostos.

Conforme disposto na Constituição, em seu artigo 153 (BRASIL, 1988), o IPI é tributo de competência da União e possui como fato gerador, conforme já definido por seu próprio nome, a industrialização de determinado bem ${ }^{4}$. Para tanto, de acordo com o artigo $4^{\circ}$ do Decreto 7.212 (BRASIL, 2010), é necessário que o bem seja objeto de esforço humano no sentido de alterar a natureza, o funcionamento, o acabamento, a apresentação ou a finalidade do produto ou o aperfeiçoe para consumo.

A base de cálculo do IPI, em regra, é definida pelo valor da operação de venda do produto industrializado, e as alíquotas são estabelecidas na Tabela de Incidência de IPI (TIPI). Salienta-se que as principais características do IPI podem ser assim relacionadas: é um tributo incidente sobre o consumo; não cumulativo ${ }^{5}$ (BRASIL, 1988); seletivo de acordo com a essencialidade do bem (tributar-se-á de forma mais gravosa os bens considerados supérfluos) e considerado um tributo indireto, pois o valor do imposto é repercutido ao consumidor final.

Já o ICMS é de competência dos Estados-Membros e do Distrito Federal e é o tributo mais importante considerando a capacidade de arrecadação tributária em nosso país, sendo responsável por onerar o consumo de bens e os serviços de transporte interestadual e intermunicipal e de comunicação, ainda que tais operações se iniciem no exterior.

Tem por base de cálculo o valor da operação de circulação do bem ou da prestação do serviço, incluídos nisso os encargos financeiros nos

\footnotetext{
${ }^{4}$ O Código Tributário Nacional (CTN) prevê ainda, como fato gerador do tributo, (a) o desembaraço aduaneiro do produto, quando de procedência estrangeira; e (b) sua arrematação, quando apreendido ou abandonado. Tal dispositivo, no entanto, não é unanimidade, visto que recebe severas críticas por parte da doutrina. Nesse sentido, conferir Melo (2011, p. 108-115).

${ }^{5}$ Conforme o artigo 153, $\S 3^{\circ}$, II da Constituição Federal. (BRASIL, 1988)
} 
pagamentos a prazo, o valor correspondente a seguros, juros e demais importâncias pagas, recebidas ou debitadas, bem como os descontos recebidos sob essa condição ${ }^{6}$ (BRASIL, 1996), e o eventual frete, caso o transporte do bem seja feito pelo próprio remetente ou por terceiro, por sua conta e ordem, e seja cobrado em separado ${ }^{7}$.

É necessário ressaltar que o montante do ICMS integra a sua própria base de cálculo. Isso ficou convencionado, de forma eufemística, como "cálculo por dentro". Mesmo que seja legal ${ }^{8}$, essa prática acaba por mascarar a alíquota real do imposto, que sempre supera a sua nominal, prejudicando a transparência do verdadeiro peso do tributo no consumo final da mercadoria e configurando uma espécie de aumento das alíquotas por via transversa ${ }^{9}$.

Em resumo, o ICMS é um tributo sobre o consumo, não cumulativo, indireto, poderá ser seletivo de acordo com a essencialidade da matéria tributada e suas alíquotas são fixadas considerando se a operação é interna ou interestadual.

O terceiro e último tributo sobre o consumo que aqui será tratado é o ISS, tributo de competência dos municípios e do Distrito Federal, como dispõe o artigo 156, III da Constituição Federal. Ele incide sobre serviços remunerados prestados a terceiros, que estejam especificados na Lista Anexa da Lei Complementar (LC) 116/2003 e que não sejam objeto de tributação pelo ICMS.

Sua base de cálculo é o preço contratado para a execução do serviço, entendido como receita bruta dele originada, e suas alíquotas máximas, de 5\%, e mínimas, de 2\%, são fixadas na LC 116/2003 e no Ato das Disposições Constitucionais Transitórias, respectivamente.

\footnotetext{
${ }^{6}$ Lei Complementar n. 87/96, artigo 13, §1º, II, a. (BRASIL, 1996)

${ }^{7}$ Não estará incluído no montante o valor pago a título de IPI quando a operação, realizada entre contribuintes e relativa a produto destinado à industrialização ou à comercialização, configurar fato gerador de ambos os impostos.

${ }^{8}$ Prevista na Emenda Constitucional 33, de 11 de dezembro 2001. (BRASIL, 2001)

${ }^{9}$ Exemplo: no Brasil uma alíquota nominal de $25 \%$ implica em uma alíquota real de $33,33 \%$. Na União Europeia, em tributos sobre o consumo, a alíquota nominal é a alíquota real.
} 
Como o valor do ISS também pode ser repercutido no valor final do serviço, transferindo-se o ônus para o contribuinte de fato, consideramos que é um tributo indireto. Além dessa característica, é importante notar que, diferente do IPI e do ICMS, esse tributo é cumulativo e, em relação à seletividade, não há previsão legal, o que não impede do ente tributante optar, nos limites das alíquotas mínima e máxima, pela seletividade em função da essencialidade do serviço prestado, o que contribuiria para a construção de uma matriz tributária progressiva ou para a redução do grau de regressividade.

O IPI, o ICMS e o ISS, de competência respectiva da União, estados e municípios, podem ser considerados "típicos" tributos sobre o consumo. Existem outros tributos e outras espécies tributárias que incidem sobre o consumo, mas estes não serão objeto de estudo no presente artigo pela especificidade da discussão. Contudo, cabe mencionar que consideramos o Imposto sobre Operações de Crédito, Câmbio e Seguros, ou relativas a Títulos ou Valores Mobiliários (IOF), o Programa de Integração Social (PIS) e a contribuição para o financiamento da seguridade social (COFINS) como tributos que repercutem ao consumidor final o ônus suportado, podendo ser incluídos, portanto, nos tributos que incidem sobre o consumo.

Tecidas essas considerações breves acerca desses principais tributos, que têm como base de incidência o consumo de bens e serviços, faremos, no próximo tópico, uma análise da tributação brasileira sob a ótica do princípio da capacidade contributiva.

\section{A Tributação sob o Ponto de Vista do Princípio da Capacidade Contributiva}

O poder conferido ao Estado de cobrar de seus cidadãos os meios para a sua manutenção encontra limites, pois, caso contrário, teríamos uma situação de enorme insegurança frente ao poder estatal de cobrar os tributos que bem entendesse. Era o que ocorria antes da construção do Estado moderno, que tem como uma das características mais importantes a cisão em definitivo entre o Estado e a propriedade. 
Em um Estado Constitucional, é de enorme importância o respeito às regras do jogo tanto por parte dos cidadãos quanto por parte do próprio Estado. Assim, esse ente político pode instituir e cobrar tributos apenas dentro dos limites estabelecidos pelo ordenamento jurídico.

Nesse sentido, os princípios tributários e as imunidades tributárias servem de proteção ao contribuinte frente à inerente avidez do Estado de exercer o seu poder de tributar. Trataremos aqui dos princípios tributários e, nesse sentido, é necessário, preliminarmente, saber o que os juristas entendem por princípio jurídico.

O convívio humano é permeado e balizado por um conjunto de valores, formado por valores sociais, culturais, econômicos, políticos etc. Esse conjunto de valores muitas vezes também é designado de conjunto axiológico do indivíduo ou da coletividade. Os valores maiores, preponderantes, mais importantes, podem ser considerados princípios. Assim, pode-se entender que um princípio é um valor fundamental de uma sociedade.

Entende-se então, por princípios jurídicos, aqueles valores que melhor fundamentam a ideia de que, no convívio humano, há a necessidade de um regramento, de normas que estabeleçam os limites dessa convivência, pois

[...] é sabido que o direito não trabalha apenas com regras, isto é, com preceitos cuja hipótese de incidência é bem circunscrita. Labora também por meio de princípios de significativa abstração, mas de irradiação por um número muito grande de situações. [...] os princípios conferem critério de interpretação para as meras regras. (BASTOS, 1994, p. 188)

Quando um princípio jurídico está na seara do direito tributário, ele passa a ser denominado princípio tributário e será o norteador de todas as atividades desenvolvidas pelo cidadão, na condição de contribuinte, e pelo Estado, na condição de ente tributante.

Os princípios tributários mais reconhecidos e importantes são: princípio da legalidade, princípio da anterioridade, princípio da irretroativida- 
de, princípio da transparência tributária e princípio da capacidade contributiva.

Entre esses princípios, destaca-se o princípio da capacidade contributiva. Por meio dele, o legislador apresenta, de forma explícita, como será apurada a possibilidade de contribuição de cada cidadão-contribuinte, permitindo que o estabelecimento da contribuição dos cidadãos para o financiamento do Estado seja compatível com sua capacidade econômica.

A capacidade contributiva, nas palavras de Paulo de Barros Carvalho,

[...] tem o condão de denotar dois momentos distintos no direito tributário. Realizar o princípio pré-jurídico da capacidade contributiva absoluta ou objetiva retrata a eleição, pela autoridade legislativa competente, de fatos que ostentem signos de riqueza. Esta é a capacidade contributiva que, de fato, realiza o princípio constitucionalmente previsto. Por outro lado, também é capacidade contributiva, ora empregada em acepção relativa ou subjetiva, a repartição da percussão tributária, de tal modo que os participantes do acontecimento contribuam de acordo com o tamanho econômico do evento. Quando empregada no segundo sentido, embora revista caracteres próprios, sua existência está intimamente ilaqueada à realização do princípio da igualdade, previsto no art. $5^{\circ}$, caput, do Texto Supremo. Todavia, não custa reiterar que este só se torna exeqüível na exata medida em que se concretize, no plano pré-jurídico, a satisfação do princípio da capacidade absoluta ou objetiva, selecionando o legislador ocorrências que demonstrem fecundidade econômica, pois, apenas desse modo, terá ele meios de dimensioná-las, extraindo a parcela pecuniária que constituirá a prestação devida pelo sujeito passivo, guardadas as proporções de ocorrência. (CARVALHO, 2007, p. 182-183)

Em relação à sua previsão constitucional, entendemos aqui que a expressão "sempre que possível", contida no parágrafo primeiro, artigo 145, da Constituição Federal, implica o dever de a administração tributária identificar a condição econômica dos contribuintes. 
Caso ocorra de a administração tributária não poder identificar as condições econômicas do contribuinte ou as identifique de forma equivocada, cabe ao contribuinte prejudicado e sem as condições de arcar com o ônus tributário invocar o princípio da capacidade contributiva.

O respeito e a aplicação do princípio da capacidade contributiva implicam respeito também ao princípio da igualdade tributária, pois, no que tange à sua capacidade econômica, os iguais igualmente devem ser tratados e aqueles que se encontram em situação de desigualdade devem ser desigualmente tratados pelo fisco.

O princípio da capacidade contributiva guarda, ainda, relação estreita com a ideia de existência de um mínimo vital e da proibição ao confisco ${ }^{10}$. Tais diretrizes auxiliam na delimitação dos contornos da atividade estatal, proibindo os excessos da tributação e garantindo o mínimo existencial como condição de dignidade do cidadão, sob pena de tornar-se o tributo confiscatório e de afrontar flagrantemente os direitos fundamentais do cidadão.

Como limite inferior da capacidade contributiva, poder-se-ia falar no mínimo vital ou mínimo existencial, de modo que não há que se falar em capacidade contributiva aquém desse mínimo. Somente depois de satisfeito esse mínimo, há a capacidade contributiva e, por conseguinte, poderá haver tributação. Por sua vez, como limite superior, temos a proibição ao confisco, isto é, a proibição ao excesso da tributação.

Entendemos por mínimo existencial a parcela mínima de direitos constitucionais básicos para a sobrevivência digna do cidadão e de sua família, que se configura como um espaço do contribuinte intributável pelo Estado. Apesar de não estar expresso na Constituição, como ocorre com a vedação ao confisco, não se pode negar a proteção que ela lhe confere.

10 Entende-se por atividade confiscatória: “[...] o ato de apreender e adjudicar bens ao fisco, pertencentes a outrem, em virtude de transgressão ou crime, como medida punitiva, que pode decorrer de ato administrativo ou condenação judicial, fundados em lei." (FRANÇA, 1977 apud VARGAS, 2003, p. 69). E, ainda, entende-se por tributos confiscatórios aqueles que "[...] absorvem parte considerável do valor da propriedade, aniquilam a empresa ou impedem o exercício de atividade lícita e moral.” (BALEEIRO, 2005, p. 564) 
É claro que essa parcela mínima de sobrevivência digna dos cidadãos é relativa e depende das particularidades de cada contribuinte ${ }^{11}$, sendo sua mensuração algo complexo, pois envolve diversas variáveis: históricas, regionais, sociais e individuais.

Considera-se, no entanto, para essa mensuração, a existência de uma base absoluta, de um núcleo essencial, representado pelas necessidades sociais elementares e, por isso, direitos do cidadão e obrigações do Estado.

Sob essa perspectiva, assume importância singular, na teoria dos direitos fundamentais, a noção de mínimo existencial, núcleo de direitos prestacionais indispensável não apenas para a sobrevivência física do indivíduo, mas também no sentido da fruição dos direitos fundamentais. Dessa forma, a composição do problema passa por uma ponderação que leva em conta a noção de mínimo existencial.

Nesse sentido:

A relação necessária entre vedação de efeitos confiscatórios e capacidade contributiva encontra-se em que os tributos não podem exceder à força econômica do contribuinte. Deve haver, então, clara relação de compatibilidade entre as prestações pecuniárias, quantitativamente delimitadas na lei, e a espécie de fato - signo presuntivo de riqueza - (na feliz expressão de A. A. Becker) posto na hipótese legal. A capacidade econômica de contribuir inicia-se após a dedução dos gastos necessários à aquisição, produção e manutenção da renda e do patrimônio, assim como do mínimo indispensável a uma existência digna para o contribuinte e sua família. (BALEEIRO, 2005, p. 574)

Muito embora o cidadão deva contribuir para manutenção do Estado e da própria sociedade, o sistema tributário, por seu lado, deve pro-

\footnotetext{
11 "O mínimo existencial, de acordo com a carta constitucional, abrange a garantia de atendimento das necessidades vitais básicas vinculadas a moradia, alimentação, saúde, lazer, vestuário, higiene, transporte e previdência social, depois de atendido a tais necessidades, pode o cidadão ser apontado como possível contribuinte, antes não; e deve o Legislador observar, ao instituir ou majorar tributos, exatamente estes pontos e garantilos, sob pena de ofensa ao princípio ora sob análise". (DUTRA, 2008, p. 120)
} 
porcionar as condições mínimas de sobrevivência desse cidadão e manter um mínimo patrimonial para que este possa continuar a gerar riquezas aptas a serem tributadas ${ }^{12}$. Dessa forma, a efetiva capacidade do cidadão de contribuir economicamente com a manutenção e atividades desenvolvidas pelo Estado deve ser sempre respeitada, sob pena de tornar nossa matriz tributária mais regressiva. Assim, no próximo ponto, pretendemos analisar se a tributação sobre o consumo respeita ou não a capacidade contributiva dos brasileiros, bem como apresentaremos um conjunto de sugestões com o objetivo de reduzir a iniquidade da matriz tributária brasileira atual.

\section{Cenário Atual: o peso da tributação sobre o consumo na renda da população e possíveis alternativas}

Como visto, das bases de incidência dos tributos, a que incide sobre o consumo representa, atualmente, a parcela mais significativa da carga tributária no Brasil, diferenciando-se da tendência observada nos países desenvolvidos, que tributam mais a renda. Tais dados são corroborados por estudos do Instituto de Pesquisa Econômica Aplicada (IPEA) ${ }^{13}$, que apontam a tributação sobre o consumo como a principal fonte arrecadadora de nosso país. Em segundo lugar, encontra-se a tributação sobre os salários, qual seja, o Imposto de Renda, a Contribuição Previdenciária e a Contribuição Sindical. Por fim, a tributação sobre o capital e outras rendas.

Ademais, observa-se que no Brasil a distribuição do ônus tributário não se dá de modo homogêneo. Estudos do IPEA têm demonstrado que o sistema tributário brasileiro tributa proporcionalmente mais os mais pobres, sendo, portanto, marcado pela regressividade dos impostos.

\footnotetext{
12 Deve-se observar também que a onerosidade em excesso é fator desestimulante ao desenvolvimento econômico e à produção, podendo trazer consequências desastrosas para a economia do país.

13 Como anteriormente salientado, esses impostos e contribuições incidem sobre o consumo, pois o ônus tributário é repercutido ao consumidor final no preço dos bens e serviços.
} 
Tomando como base o salário mínimo, por exemplo, observa-se que as famílias com renda de até dois salários mínimos pagam $48,8 \%$ da sua renda em tributos. Já as famílias com renda acima de 30 salários mínimos pagam aproximadamente $26,3 \%{ }^{14}$, poupando relativamente mais.

Assim, basicamente, o contribuinte destinou, em média, 132 dias do ano comercial para o pagamento de tributos. Os cidadãos mais pobres, no entanto, trabalharam o equivalente a 197 dias, enquanto os cidadãos mais ricos aportariam 106 dias, comparativamente.

Em termos absolutos, portanto, a carga tributária incidente sobre as famílias de baixa renda é relativamente mais alta, reduzindo significativamente seu poder de compra e, com isso, desrespeitando o princípio da capacidade contributiva e afetando diretamente o mínimo existencial.

O Fato é que os países em desenvolvimento seguem a tendência de concentrar suas arrecadações nos tributos embutidos no preço final das mercadorias e serviços, isto é, tributam mais o consumo da população. Ocorre que, em respeito ao princípio da capacidade contributiva, urge a viabilização de melhoria do sistema de acordo com as necessidades econômico-sociais de sua população.

Conforme aqui ficou demonstrado, o Brasil apresenta uma matriz tributária altamente regressiva, na qual as pessoas com menor capacidade contributiva arcam com a maior parte dos tributos arrecadados em nosso país. Isso se dá, em boa parte, devido à importância dada à incidência de tributos sobre o consumo de bens e serviços. Em geral, esse tipo de tributação não considera a capacidade contributiva do indivíduo para efeitos de tributação, o que acaba por ser responsável pela maior parte do ônus atribuído às camadas menos abastadas de nossa população.

\footnotetext{
14 Segundo estudos realizados pelo Departamento Intersindical de Estatística e Estudos Socioeconômicos (DIEESE), o salário mínimo necessário, isto é, aquele em conformidade com o preceito constitucional citado, está muito acima do salário mínimo nominal pago aos trabalhadores brasileiros. No mês de março de 2010, por exemplo, o salário mínimo vigente era de $\mathrm{R} \$ 510,00$, enquanto o salário mínimo necessário, mensurado pela DIEESE com base no maior valor da ração essencial e na ponderação do gasto familiar, deveria ser R\$ 2.159, 65.
} 
Tal constatação significa dizer que, em certa medida, os problemas de distribuição de renda no Brasil são frutos de uma matriz tributária regressiva. Para melhor precisar: a população brasileira estimada no ano de 2010 era de cerca de 190 milhões. Destes, 16,2 milhões eram considerados miseráveis (em extrema pobreza), ou seja, que têm renda mensal de um a setenta reais ${ }^{15}$

O programa de transferência direta de renda do governo federal denominado "bolsa família", que atende às famílias em situação de pobreza (com renda mensal de setenta a cento e quarenta reais) e extrema pobreza, alcança mais de 13 milhões de famílias em todo o território brasileiro (BRASIL, 2010). Isso representa cerca de 50 milhões de brasileiros de um total de 190 milhões; portanto, aproximadamente $26 \%$ da população do país.

Em pesquisas realizadas pela Organização das Nações Unidas (ONU), por intermédio do Programa das Nações Unidas para o Desenvolvimento (PNUD), o Brasil ocupa a oitava posição em desigualdade social, isto é, o país ficou atrás apenas da Guatemala, Suazilândia, República Centro-Africana, Serra Leoa, Botsuana, Lesoto e Namíbia. Esses dados se referem ao ano de 2005 e contemplaram o estudo de 177 países. (BRASIL, 2011)

Combater as distorções causadas pela atual estrutura fiscal deve ser prioridade na agenda de nossa nação, uma vez que a busca pela justiça social passa, necessariamente, pela realização da justiça tributária. No entanto, tal objetivo só pode ser atingido hoje por intermédio de uma profunda mudança na estrutura da tributação, que proporcione uma melhor distribuição dos tributos existentes, principalmente aqueles incidentes sobre o consumo. Com isso, visando uma maior progressividade da matriz tributária brasileira, apresentam-se a seguir algumas alternativas viáveis ao atual modelo brasileiro ${ }^{16}$.

${ }^{15}$ Para mais detalhes, ver Brasil, Ministério do Desenvolvimento Social e Combate à Fome.

16 As presentes sugestões foram frutos de debates entre os autores e os membros do Grupo de Pesquisa: Estado, Constituição e Direito Tributário na Faculdade de Direito da UnB e refletem, de um modo geral, a opinião de todos. Não obstante, cumpre ressaltar 
O primeiro passo a ser adotado nessa reforma é a valorização do princípio da transparência tributária, elencado no artigo $150, \S 5^{\circ}$ da Constituição Federal. Conforme se depreende das lições de Amaro (2010, p. 171), os impostos sobre o consumo, por serem uma espécie de tributação indireta, acabam sendo repercutidos na cadeia produtiva e incorporados ao preço final dos bens e serviços, sem que os consumidores, contribuintes de fato do encargo fiscal, tenham noção da carga embutida. Assim, esses tipos de impostos acabam anestesiando o indivíduo acerca do que é arrecadado ao se adquirir determinado produto, uma vez que o peso do gravame fiscal acaba sendo disfarçado em seu preço ${ }^{17}$.

Embora tal medida possa parecer interessante sob um viés político eivado de má-fé, justamente por permitir uma alienação do contribuinte acerca da carga tributária paga, essa situação não contribui de maneira alguma para a formação social do cidadão, nem para sua conscientização acerca do que é arrecadado e de como esses recursos são empregados. Dessa forma, fica evidente a importância do combate da pouca transparência observada atualmente.

A efetivação desse princípio constitucional se dá, entre outras maneiras, por intermédio da exclusão do montante do imposto de sua própria base de cálculo, combatendo aquilo que é conhecido por cálculo por dentro como já salientado quando se tratou das questões relativas ao ICMS, principal tributo sobre o consumo no Brasil. Essa forma de calcular o tributo por dentro cria uma distorção entre a alíquota nominal do imposto

que essa vem sendo a tendência observada nas diversas discussões que envolvem o tema da reforma tributária de nosso país. Também vale destacar que as alternativas aqui apresentadas não pretendem, de maneira alguma, esgotar as possibilidades, reconhecendo a existência de muitas outras que só enriquecem o debate acadêmico. Assim, ao tratar do assunto, os autores pedem compreensão do leitor, uma vez que a amplitude do tema jamais poderia ser abordada nessas poucas linhas.

17 Nesse sentido “[...] cabe notar que esse efeito de 'anestesia fiscal' é bastante perceptível nos tributos indiretos em que a regra é a repercussão econômica dos tributos, e esta é a que lhes confere a espécie. Nos tributos diretos, pela ausência de repercussão, cada contribuinte tem como aferir de pronto o montante de tributo que está pagando. Dessa percepção decorre que os tributos indiretos são denominados muitas vezes de tributos 'anestesiantes' e os diretos de 'irritantes"'. (GASSEN, 2004, p. 120) 
e sua alíquota real, uma vez que a carga fiscal efetivamente paga é bem maior do que a prevista no texto legal.

Outra maneira de se contribuir para uma maior transparência tributária seria por intermédio da simplificação do sistema de arrecadação, com uma possível unificação dos tributos sobre o consumo em torno de um único imposto sobre o valor agregado.

O que se observa hoje é que a estrutura fiscal brasileira, no que diz respeito à tributação sobre o consumo, é um emaranhado de legislações federais, estaduais e municipais. Essa diversidade normativa contribui para a criação de um ambiente confuso e com baixa coordenação entre os entes federativos responsáveis pela arrecadação, que gera, por sua vez, um custo adicional aos contribuintes, principalmente os chamados contribuintes de fato.

A uniformização da cobrança permitiria assim, entre outras vantagens, uma maior simplicidade do sistema, facilitando sua compreensão pelo contribuinte e efetivando uma maior transparência. Permitiria também o aumento da eficiência econômica e melhoria na alocação de recursos, uma vez que facilitaria a arrecadação e fiscalização por meio de uma estrutura única em todo o território nacional. Dessa forma, combateria a evasão e a sonegação fiscal, aumentando o montante a ser recolhido pelo Estado. Além disso, possibilitaria ainda uma maior harmonização e integração do Brasil com seus demais parceiros do MERCOSUL, visto que nosso país é o único do bloco a possuir mais de um imposto sobre circulação e consumo.

No que diz respeito ao consumidor, essa racionalização do sistema de arrecadação poderia resultar numa redução das alíquotas e consequente redução do preço final dos produtos consumidos. Como mencionado, com a otimização dos recursos depreendidos e a redução da evasão fiscal, seria possível uma redução das alíquotas sem reduzir o montante arrecadado, favorecendo, assim, o contribuinte de fato e colaborando para o estabelecimento de um sistema tributário mais justo.

A não cumulatividade representa outra forma de se atingir maior justiça fiscal pela implementação de medidas que desonerem o setor pro- 
dutivo e, consequentemente, contribuam para a redução do gravame fiscal final incidente no bem ou serviço. A adoção desse princípio permitiria, ainda, um aumento da produtividade e eficiência com respectiva redução dos custos de produção, por meio de uma desverticalização da economia. Todas essas consequências refletiriam na redução do preço final dos bens e serviços de consumo, beneficiando, assim, o contribuinte de fato.

Outra medida que pode contribuir para a correção de desigualdades sociais é a adoção de uma alíquota proporcionalmente maior para os Estados de destino nas transações interestaduais. Esta opção pode resultar em uma maior transferência de recursos para os Estados menos desenvolvidos da Federação, contribuindo para a redução das distorções regionais observadas no nosso país hoje. Ademais, tal proposta pode trazer reflexos positivos no combate à chamada guerra fiscal, na qual unidades da Federação barganham a instalação de parques industriais em seus territórios através da concessão de benefícios fiscais irregulares para as grandes sociedades empresárias.

Ainda objetivando a obtenção de uma maior justiça fiscal, há de se ressaltar a importância de que se implemente uma maior observância do princípio da seletividade na tributação sobre o consumo. Este princípio permite a variação da alíquota do imposto de acordo com a essencialidade do bem, proporcionando, assim, uma tributação mais pesada sobre bens e serviços considerados supérfluos, bem como uma atenuação daqueles produtos considerados de primeira necessidade. Com isso, ele visa estabelecer os impostos de acordo com a presumível capacidade contributiva do indivíduo.

Hoje, no Brasil, o que se observa é que, por força de lei, apenas o IPI será necessariamente seletivo, enquanto o ICMS "poderá ser seletivo" e, em relação ao ISS, nada se dispõe. O disposto na Constituição de que o ICMS, considerando a essencialidade dos bens e serviços, objeto do gravame tributário, pode ser seletivo e, não o sendo pela legislação estadual e distrital, fere os objetivos a serem alcançados pela República ${ }^{18}$ de, por

18 “Art. $3^{\circ}$ Constituem objetivos fundamentais da República Federativa do Brasil: I construir uma sociedade livre, justa e solidária; II - garantir o desenvolvimento nacional; III - erradicar a pobreza e a marginalização e reduzir as desigualdades sociais e regionais; 
exemplo, erradicar a pobreza, pois os pobres e miseráveis em termos econômicos são os mais atingidos pela regressividade da matriz tributária brasileira.

No entanto, em que pese tal determinação normativa, é de se entender que, por intermédio de uma leitura sistemática dos princípios constitucionais, a fixação das alíquotas de todos esses tributos incidentes sobre o consumo deve obedecer à seletividade. Dessa forma, produtos essenciais para o consumo do cidadão comum, como alimentos presentes na cesta básica, devem ter sua alíquota reduzida (e por que não zerada), de modo a equilibrar a matriz tributária brasileira, reduzindo o ônus fiscal sobre a população menos abastada.

Como observa Amaro (2010, p. 164-165), a observância da seletividade amolda o imposto ao princípio universal da capacidade contributiva, atenuando a regressividade característica desse tipo de tributo. Assim, permite-se que a fixação das alíquotas atenda às características do contribuinte de fato (real responsável pelo encargo fiscal), transformando a tributação sobre o consumo em importante ferramenta de combate às desigualdades existentes em nossa sociedade.

Por fim, há que se ressaltar que as propostas elencadas até aqui proporcionam, de um modo geral, uma redução das alíquotas incidentes sobre bens e serviços. Essa consequência vem casada com o intuito de se buscarem formas de reequilibrar a matriz tributária brasileira, tornando-a cada vez menos regressiva. No entanto, a diminuição das alíquotas gera não só uma melhor distribuição do ônus fiscal, como também pode produzir outros resultados satisfatórios para nossa sociedade.

Longe de representar uma perda na arrecadação do Estado, a redução das alíquotas pode significar um estímulo ao consumo, que acarreta um estímulo à produção, proporcionando um crescimento sustentável da economia, com a consequente criação de novos postos de empregos, transformando-se em um verdadeiro círculo virtuoso, que traz benefícios para toda a sociedade.

IV - promover o bem de todos, sem preconceitos de origem, raça, sexo, cor, idade e quaisquer outras formas de discriminação". (BRASIL, 1988) 
Dessa forma, mesmo diminuindo a alíquota, poderíamos observar um aumento geral na arrecadação, de modo que a tributação sobre o consumo continuaria a exercer grande influência na matriz tributária brasileira, mas de uma maneira mais progressiva, atendendo ao princípio da capacidade contributiva. Assim, reequilibraríamos a matriz tributária brasileira, a fim de melhor distribuir o encargo fiscal em nossa sociedade, deixando de onerar mais aquela fração da população que menos deveria contribuir.

\section{Conclusões}

Conforme exposto neste artigo, a tributação sobre o consumo representa hoje a principal fonte de receitas do Estado brasileiro. Atualmente, mais da metade da arrecadação tributária incide de alguma forma na cadeia produtiva, sendo repassadas, dessa forma, ao consumidor final por intermédio de mecanismos que repercutem economicamente o ônus fiscal no preço final de bens e serviços.

Como consequência nefasta dessa escolha, acaba-se gerando uma matriz tributária altamente regressiva, o que contribui enormemente no aprofundamento do abismo social existente em nosso país, que, diga-se de passagem, é um dos mais desiguais do mundo. Em uma clara violação ao princípio da capacidade contributiva, busca-se no Brasil, por meio da tributação sobre o consumo, tributar de forma mais onerosa as camadas mais pobres da população, fazendo com que elas sustentem, em grande medida, o Estado brasileiro.

Essa realidade fere, assim, um pressuposto lógico e óbvio seguido pela grande maioria dos países desenvolvidos: onerar conforme a capacidade econômica de cada um. Com isso, nega-se à grande parte de nossa população o mínimo existencial que garanta seus meios de subsistência, comprometendo a existência digna desses cidadãos.

Dessa forma, é necessário discutir meios de se reformular a matriz tributária, de maneira a melhor distribuir o ônus fiscal em nossa sociedade, sendo essa a proposta do presente artigo. Ao buscar alternativas que visam diminuir a alta regressividade de nosso sistema tributário, preten- 
demos levantar esta séria questão de modo que ela não fique restrita a meros debates acadêmicos. Temos que nos conscientizar do papel que a tributação exerce em nossa sociedade e, como cidadãos comprometidos com a busca de uma maior justiça social, exigir as mudanças necessárias para tornar o Brasil um país menos desigual. Afinal, como dito anteriormente, combater as distorções sociais deve ser prioridade na agenda de nossa nação, e a busca pela justiça social passa, necessariamente, pela remodelação de nossa atual estrutura fiscal e, consequentemente, pela realização de uma maior justiça tributária.

\section{Referências}

AMARAL, Antonio Carlos Rodrigues do. Imposto sobre Produtos Industrializados - IPI - e o Imposto sobre Circulação de Mercadorias e Serviços de Transporte Interestadual, Intermunicipal e de Comunicação - ICMS. In: JARDIM, Eduardo Macial Ferreira; PASIN, João Bosco Coelho. Tributos em espécie. Rio de Janeiro: Elsevier, 2010.

AMARO, Luciano. Direito Tributário Brasileiro. 16. ed. São Paulo: Editora Saraiva, 2010.

ÁVILA, Humberto. Teoria da Igualdade Tributária. São Paulo: Editora Malheiros, 2008.

BALEEIRO, Aliomar. Limitações constitucionais ao poder de tributar. Rio de Janeiro: Editora Forense, 2005.

BASTOS, Celso Ribeiro. Curso de direito financeiro e de direito tributário. 3. ed. São Paulo: Saraiva, 1994. (p. 188)

BORGES, José Cassiano; REIS, Maria Lucia Américo dos. Manual de operações e prestações com impostos indiretos: IPI, ICMS, ISS. Rio de Janeiro: Esplanada: ADCOAS, 1994.

BRASIL. Constituição (1988). Constituição da República Federativa do Brasil. Brasília, DF: Senado, 1988. 
. Constituição (1988). Emenda Constitucional 33, de 11 de dezembro de 2001. Altera os artigos 149, 155 e 177 da Constituição Federal. Diário Oficial [da] República Federativa do Brasil. Poder Executivo, Brasília, DF, 12 dez. 2001. p. 15. Disponível em: $<$ http:// www.planalto.gov.br/ccivil_03/constituicao/Emendas/Emc/emc33.htm>. Acesso em: 24 out. 2011.

. Decreto n. 7.212, de 15 de junho de 2010. Regulamenta a cobrança, fiscalização, arrecadação e administração do Imposto sobre Produtos Industrializados - IPI. Diário Oficial da União. Poder Executivo, Brasília, DF, 16 jun. 2010. p. 4. Disponível em: $<$ http://www. planalto.gov.br/ccivil_03/_ato2007-2010/2010/decreto/d7212.htm>. Acesso em: 20 out. 2011.

. Ministério do Desenvolvimento Social e Combate à Fome.

\section{O perfil da Extrema Pobreza no Brasil com base nos dados} preliminares do universo do Censo 2010. Nota MDS, 2 mai. 2011. Disponível em: <http:/www.brasilsemmiseria.gov.br/wp-content/ themes/bsm2nd/perfil_extrema_pobreza.pdf $>$ e http://www.mds.gov.br/ bolsafamilia> . Acesso em: 26 out. 2011.

. Lei Complementar n. 116, de 31 de julho de 2003. Dispõe sobre o Imposto Sobre Serviços de Qualquer Natureza, de competência dos Municípios e do Distrito Federal, e dá outras providências. Diário Oficial da União, Brasília, DF, $1^{\circ}$ ago. 2003. Disponível em: <www2. camara.gov.br/legin/fed/leicom/2003/leicomplementar-116-31-julho2003-492028-norma-pl.html>. Acesso em 25 out. 2011.

. Lei Complementar n. 87, de 13 de setembro de 1996. Dispõe sobre o imposto dos Estados e do Distrito Federal sobre operações relativas à circulação de mercadorias e sobre prestações de serviços de transporte interestadual e intermunicipal e de comunicação, e dá outras providências. Diário Oficial da União, Brasília, DF, 16 set. 1996, p. 218.261.

CARVALHO, Paulo de Barros. Curso de Direito Tributário. 19. ed. São Paulo: Saraiva, 2007. 


\section{COÊLHO, Sacha Calmon Navarro. Curso de Direito Tributário brasileiro. Rio de Janeiro: Forense, 2009.}

DIEESE. Departamento Intersindical de Estatística e Estudos Socioeconômicos. [2010]. Disponível em: $<$ http://www.dieese.org.br $>$. Acesso em: 20 mar. 2010.

DUTRA, Micaela Dominguez. A aplicação do princípio da capacidade contributiva aos tributos no sistema tributário nacional. Revista Fórum de Direito Tributário, Editora Fórum, n. 35. p. 115-137, 2008.

GASSEN, Valcir. A tributação do consumo. Florianópolis: Momento Atual, 2004.

MELO, José Eduardo Soares. IPI. In: MARTINS, Ives Gandra da Silva (Org.) Curso de Direito Tributário. São Paulo: Saraiva, 2011.

OCDE. Revenue Statistics 1965-2008. Disponível em: $<$ http:// www.oecd-ilibrary.org/taxation/revenue-statistics-2009/tax-revenuetrends-1965-2008_rev_stats-2009-3-en-fr>. Acesso em: 18 abr. 2011. VARGAS, Jorge de Oliveira. Princípio do não-confisco como garantia constitucional da tributação justa. Curitiba: Juruá, 2003.

Valcir Gassen possui Pós-Doutorado pela Universidade de Alicante - Espanha. É Doutor e Mestre em Direito pela Universidade Federal de Santa Catarina (UFSC) e Graduado em Direito pela Universidade Regional do Noroeste do Estado do Rio Grande do Sul (UNIJUI). Professor adjunto da Universidade de Brasília (UnB). E-mail: gassen@unb.br.

Endereço profissional: Universidade de Brasília. Faculdade de Direito. Campus Universitário Darcy Ribeiro. CEP: 70.910-900. Asa Norte, Brasília/DF.

Pedro Júlio Sales D’Araújo é Graduando na Faculdade de Direito da Universidade de Brasília (UnB).E-mail: salesdaraujo@gmail.com.

Endereço profissional: Universidade de Brasília. Faculdade de Direito. Campus Universitário Darcy Ribeiro. CEP: 70.910-900. Asa Norte, Brasília/DF. 
Sandra Regina da F. Paulino é Graduanda na Faculdade de Direito da Universidade de Brasília (UnB).E-mail: sfpaulino15@gmail.com.

Endereço profissional: Universidade de Brasília. Faculdade de Direito. Campus Universitário Darcy Ribeiro. CEP: 70.910-900. Asa Norte, Brasília/DF. 